\title{
Antioxidant, Antimicrobial Activities and Phenolic and Chemical Contents of Physalis peruviana L. from Trabzon, Turkey
}

\author{
Ömer ERTÜRK ${ }^{1}$, Melek ÇOL AYVAZ ${ }^{2 *}$, Zehra CAN${ }^{3}$, Ülkü KARAMAN ${ }^{4}$ Kürşat KORKMAZ ${ }^{5}$ \\ 1'Department of Biology, Faculty of Art and Science, Ordu University, Ordu, TURKEY \\ ${ }^{2}$ Department of Chemistry, Faculty of Art and Science, Ordu University, Ordu, TURKEY \\ 3Şebinkarahisar Technical Sciences Vocational School,Giresun University, 28400, Giresun, TURKEY \\ ${ }^{4}$ Department of Medical Parasitology, Faculty of Medicine, Ordu University, Ordu, TURKEY \\ ${ }^{5}$ Department of Soil Science and Plant Nutrition, Faculty of Agriculture, Ordu University, Ordu, TURKEY
}

\begin{abstract}
Background: Goldenberry (Physalis peruviana L.) is one of the most promising exotic fruits in terms of its biological capacity. Objective: In this work, ethanol extracts of the different parts (fruit, seed, root, body and leaf) of the $P$. peruviana were investigated in terms of their antioxidant and antimicrobial activity. Furthermore total phenolic and flavonoid contents, phenolic analysis and volatile compound analysis were exhibited. Method: Total phenolic and flavonoid contents were calculted as gallic acid and quercetin equivalent respectively. Antioxidant activity were studied based on DPPH free radical scavenging activity. Antimicrobial activity were determined by disc diffusion method against several bacteria, a fungi and a yeast. Analysis for phenolic and volatile compounds were exhibited by using HPLC and GC-MS respectively. Results: The values obtained for the total phenolic and flavonoid contents and $\mathrm{SC}_{50}$ values calculated for DPPH scavenging activities were compatible with each other. Extract prepared from the seed had the highest phenolic (4.956 $\pm 0.001 \mathrm{mg} \mathrm{GA} / \mathrm{g}$ sample) and flavonoid content $(0.737 \pm 0.034$ $\mathrm{mg} \mathrm{QE} / \mathrm{g}$ sample). Gallic acid and ferulic acid were detected in all extracts. The most volatile species (190 pieces) detected in root extract. Seed and fruit were the most effective parts of the $P$. peruviana in terms of their antimicrobial activity. Conclusion: According to obtained results it has been demonstrated that $P$. peruviana from Trabzon had good useful properties for human health and it would be useful to carry out further researchs on it.
\end{abstract}

Keywords: Antioxidant, Antimicrobial, Physalis peruviana L, DPPH, HPLC, GC-MS.

\section{INTRODUCTION}

Physalis peruviana Linnaeus which is belonging to the family Solanaceae and genus Physalis is a medicinal plant widely used in folk medicine to treate diseases such as malaria, asthma, hepatitis, dermatitis, diuretic and rheumatism. ${ }^{1,2}$ Some of these medicinal benefits could be arised from antioxidant capacity of polyphenols present in the fruit. The beneficial effect of the plant extracts on microorganism have been exhibited by a very large number of researchers in different parts of the world. ${ }^{3}$ New antimicrobial agents are still needed to treat diseases in humans and animals caused by drug resistant microorganisms. Thanks to all these features the plant of P. peruviana was worthy to investigation. The objective of this study was to determine the antioxidant and antimicrobial activities and biochemical components of the leaf, fruit, seed, body and root portions of the $P$. peruviana L. grown in Trabzon, Turkey.

\section{MATERIALS AND METHODS}

Plant material and extract preparation

P.peruviana were collected from Trabzon province of Turkey in August 2015. The
DOI: 10.5530/ijper.51.3s.15 Correspondence: Melek COL AYVAZ,

Department of Chemistry, Faculty of Art and Science, Ordu University, Ordu, TURKEY

Contact Number: 90452234 5010 (1669)

Fax: +90 4522339149 E-mail: melekcol@hotmail. com

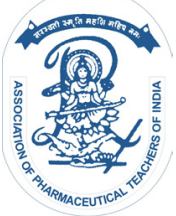

www.ijper.org 
identification of the plant was determined. ${ }^{4}$ Fruit, seed, body, leaf and root extracts of the P. perwiana were separately prepared. The crude extracts were stored at -20 ${ }^{\circ} \mathrm{C}$ until used.

\section{Antimicrobial analysis}

The antimicrobial activity of $P$. perwiana extracts were studied by disc diffusion method ${ }^{5}$ against Staphylococcus aureus ATCC 25923, Bacillus cereus ATCC 10876, Listeria monocytogenes ATCC 7677, Clostridium perfringens ATCC 313124, Escherichia coli ATCC 25922, Klebsiella pneumoniae ATCC 13883, Pseudomonas aeruginosa ATCC 27853, Shigella sonnei ATCC 25931, Yersina enterocolitica ATCC 27729, Salmonella typhimurium ATCC 14028, Candida albicans ATCC 10231 and Aspergillus niger ATCC 9642). Mueller Hinton Agar or Broth and Sabouraud Dextrose Broth or Agar were used. For the fungi and yeast, Nystatin and for the bacteria Ampicillin and Cephazolin were used as a positive control. Alcohol was also used as negative control. Inhibition zones which formed on the medium were measured in millimeter $(\mathrm{mm})$ after incubation for $24 \mathrm{~h}$ at $37^{\circ} \mathrm{C}$ and $27^{\circ} \mathrm{C}$ for antibacterial and antifungal/antiyeast activities, respectively.

\section{Determination of total phenolic and flavonoid contents}

The phenolic content of the ethanol extract of each part of P. peruviana was assayed according to the FolinCiocalteu method modified by Singleton and Rossi. ${ }^{6}$ The total phenolic contents of the extracts were calculated as gallic acid (mg GA/g sample) equivalent.

The amount of total flavonoid was measured with a method as reported previously. ${ }^{17}$ The total flavonoid concentration was expressed as quercetin (mg QT/100 g sample) equivalent.

\section{Measurement of DPPH free radical-scavenging activity}

DPPH free radical scavenging activity of the samples was calculated by following the reduction in the absorbance (at $517 \mathrm{~nm}$ ) of DPPH solution in methanol with the addition of the samples.

\section{GC-MS and HPLC analysis}

GC-MS analysis were performed according to solid phase microextraction technique. ${ }^{8}$ Thirteen standards of phenolic compounds were analyzed following the extraction and analyse methods of Akyüz et al. ${ }^{9}$

\section{RESULTS AND DISCUSSION}

\section{Antimicrobial Activity}

According to the report of Borchardt et al. ${ }^{10}$ antimicrobial compounds of plant origin may occur in stems, roots, leaves, bark, flowers and fruits of plants. In accordance with this information, it is concluded from the measurements obtained from antimicrobial activity studies that the most effective parts of the plant were seed and fruit. Because, seed extract produced an inhibition diameter against many of the tested organisms as large as the ampicillin used as a positive control. Fruit extract was more effective than ampicillin and cephazolin against $S$. aureus. The extracts of the other parts of the P. peruviana had moderate antimicrobial activity. The values obtained can be sufficient for $P$. peruviana to be evaluated as to be used as a medicinal product for the treatment of several infectious disease.

\section{Phenolic and Flavonoid Contents}

According to calculated values it is easily seen from the Table 1 there is a high correlation between the phenolic and flavonoid contents especially in terms of fruit, seed and body parts.

\section{DPPH Free Radical Scavenging Activities of the Extracts}

To determine antioxidant activity of a material DPPH free radical scavenging activity assay were preferred because DPPH scavenging activity, total phenolic and flavonoid concentrations are complementary with each other. ${ }^{11}$ When the values from Table 2 are examined, especially the values obtained for fruit, leaf and seed are in good agreement with the values obtained for phenolic and flavonoid amounts.

\begin{tabular}{|c|c|c|}
\hline \multicolumn{2}{|c|}{ Table 1: The phenolic and flavonoid contents of the extracts from the } \\
different parts of $\boldsymbol{P}$ peruviana \\
\hline $\begin{array}{c}\text { Parts of the } \\
\text { plant }\end{array}$ & $\begin{array}{c}\text { Total phenolic content } \\
\text { (mg GA/g sample) }\end{array}$ & $\begin{array}{c}\text { Total flavonoid content } \\
\text { (mg QE/ g sample) }\end{array}$ \\
\hline Fruit & $1.505 \pm 0.002$ & $0.423 \pm 0.004$ \\
\hline Leaf & $1.368 \pm 0.012$ & $0.635 \pm 0.005$ \\
\hline Seed & $4.956 \pm 0.001$ & $0.737 \pm 0.034$ \\
\hline Body & $0.466 \pm 0.009$ & $0.294 \pm 0.004$ \\
\hline Root & $0.242 \pm 0.023$ & $0.062 \pm 0.001$ \\
\hline
\end{tabular}




\section{Table 2: $\mathbf{S C}_{50}$ values for the DPPH scavenging}

activities of the extracts

\section{Parts of the material}

Fruit

Leaf

Seed

Body

Root
$\mathrm{SC}_{50}(\mathrm{~g} / \mathrm{ml})$

0.0110

0.0080

0.0021

0.0642

0.0417

\section{Phenolic Compounds}

It was reported that phenolics are distributed differently depending on the plant part. ${ }^{12}$ Gallic acid and ferulic acid were detected in varying amounts in extracts prepared from all parts of the plant while while $p-\mathrm{OH}$ benzoic acid, epicatechin and luteolin were absent in all extracts. Fruit part of the tested material had more phenolic species than other parts. But, leaf part contained the highest amount of phenolics. P. peruviana root contained six different type of phenolics at the lowest level. Catechin and rutin were the major components of leaf of golden berry.

\section{Chemical composition analysis}

110 different compounds as an average were detected in each plant part examined. Root was the richest part in terms of compound type while the body was the poorest. The compounds identified could be grouped suh as cyclic, non-cyclic and aromatic compounds, hyrocarbons, alcohols, aldehydes, ketons, esters. Some of the compounds such as (S)-4-Iodo-1,2-epoxybutane; 1,1,1,5,7,7,7-Heptamethyl-3,3-bis(trimethylsiloxy) tetrasiloxane; 1,2-Benzenedicarboxylic acid, diethyl ester; Docosane; Eicosamethylcyclodecasiloxane; Hexane, 3,3-dimethyl-; Octane, 3,3-dimethyl- were detected in all extracts. Except these there are a wide variety of compounds known to have various clinical and useful properties in detected list. For example, 1,2,3-tri(t-Butyl) cyclopropenylium tribromide which is known antibacterial and antiviral activity was detected in the root and body, even in small quantities. Tri-o-trimethylsilyl derivative of terbutaline and tri-o-trimethylsilyl, N-heptafluorobutyryl derivative of terbutaline known to have clinical prescription and used as a fast acting bronchodilator and as a tocolytic to delay premature labor were detected in the extract prepared from the root. ${ }^{13}$ Dimethyl-flubendazole was also detected in the root extract. Flubendazole is known for its use as an antihelminthic drug in veterinary and human medicine. ${ }^{14}$

\section{CONCLUSION}

In the present study, a variety of phenolics and volatile compounds were detected in the extracts prepared from the different parts of P. perwviana collected from Trabzon. Low $\mathrm{SC}_{50}$ values calculated for DPPH free radicals scavenging capacity of extracts and high values for total phenolic and flavonoid contents could be attributed to these molecules. Furthermore, the antibacterial study results indicated that the lowest MIC values compared with known antimicrobial agents such as Ampicillin, Cephazolin and Nystatin. All these statements require further study and give encouragement.

\section{ACKNOWLEDGEMENT}

The authors are thankful to Ordu Univeresity Scientific Reseacrh Projects Commission for financial support.

\section{CONFLICT OF INTEREST}

The authors have no conflict of interest.

\section{ABBREVIATIONS USED}

GA: Gallic acid; QE:Quercetin; HPLC: Hig performance liquid chromatography; DPPH: 1,1-Diphenyl2-picrylhydrazyl radical; $\mathrm{SC}_{50}$ : The concentration that can scavenge the half of the radicals in the medium; GC-MS: Gas chromatography-mass spectrometry.

\section{REFERENCES}

1. Wu SJ, Ng LT, Huang YM, Lin DL, Wang SS, Huang SN, et al. Antioxidant Activities of Physalis peruviana. Biological and Pharmaceutical Bulletin. 2005;28(6):963-6.

2. Cedeño M, Montenegro D. Plan exportador, logístico y comercialización de uchuva al mercado de Estados Unidos para FRUTEXPO SCI Ltda. Facultad de Ingeniería, vol. Ingeniero Industrial. : Bogotá Pontificia Universidad Javeriana. 2004.

3. National Research Council (NRC). Goldenberry (Cape Gooseberry). Lost crops of the incas: Little-known plants of the andes with promise for worldwide cultivation. Washington D.C.: National Academy Press. 1989; pp: 240-251.

4. Göztok F, Zengin F. The antimicrobial activity of Physalis peruviana L. Bitlis Eren University Journal of Science and Technology. 2013;3:15-7.

5. Ertürk Ö. Antibacterial and antifungal activity of ethanolic extracts from eleven spice plants. Biologia. 2006;61(3):275-8.

6. Singleton VL, Rossi JA. Colorimetry of Total Phenolics with PhosphomolybdicPhosphotungstic Acid Reagents. American Journal of Enology and Viticulture. 1965;16(3):144-58.

7. Fukumoto LR, Mazza G. Assessing antioxidant and prooxidant activities of phenolic compounds. Journal of Agricultural and Food Chemistry. 2000;48(8):3597-604.

8. Taş B, Ertürk Ö, Yılmaz Ö, Çol Ayvaz M, Ertürk YE. Chemical components and biological activities of two freshwater green algae from Ordu, Turkey. Turkish Journal of Biochemistry. 2015;40(6):508-17.

9. Akyuz E, Sahin H, Islamoglu F, Kolayli S, Sandra P. Evaluation of Phenolic Compounds in Tiliarubra subsp. caucasica by HPLC-UV and HPLC-UV-MS/ MS. International Journal of Food Properties. 2014;17(2):331-43. 
orchardt JR, Wyse DL, Sheaffer CC, Kauppi KL, Fulcher RG, Ehlke NJ, et al. RF. Antimicrobial activity of native and naturalized plants of Minnesota and Wisconsin. Journal of Medicinal Plants Research. 2008;2(5):98-110.

11. Turkoglu A, Kivrak I, Mercan N, Duru ME, Gezer K, Turkoglu H. Antioxidant and antimicrobial activities of Morchella conica Pers. African Journal of Biotechnology. 2006;5(11):1146-50.
12. Cartea MA, Francisco M, Soengas $P$, Velasco $P$. Phenolic Compounds in Brassica Vegetables. Molecules. 2011;16(1):251-80

13. WHO. "Antenatal administration of corticosteroids for women at risk of preterm birth". WHO. Retrieved 2013-03-25.

14. Panic G, Duthaler U, Speich B, Keiser J. Repurposing drugs for the treatment and control of helminth infections. International Journal for Parasitology: Drugs and Drug Resistance. 2014;4(3):185-200

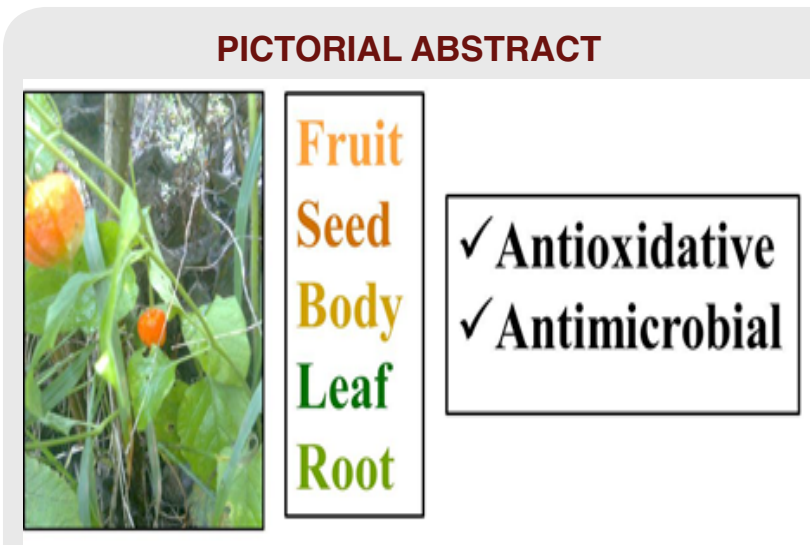

\section{SUMMARY}

- The most antimicrobial parts of the goldenberry plant were seed and fruit.

- Phenolics and flavonoids are mostly in the seed part of the plant. However, the root was the poorest.

- DPPH scavenging activities of the seed and root parts were the highest and lowest, respectively.

- Catechin and rutin were the major components of leaf of golden berry.

- Root was the richest part in terms of compound type while the body was the poorest.

\section{ABOUT AUTHORS}

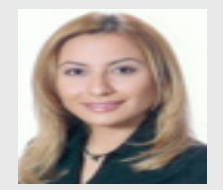

Dr. Melek COL AYVAZ Has done her PhD in chemistry from Karadeniz Technical University in 2009. Her doctoral research is focused on Cloning, expression and characterization of alkaline phosphatase from thermophilic Geobacillus caldoxylosilyticus TK4 strain. At present she is working as a assistant professor at Ordu University and studying on antioxidative activities of several edible plants and interactions between inorganic molecules and DNA. She has worked as a manager in the Project "Investigation of DNA Binding Properties, DNA Cleavage Activities, Antioxidant Capacities and In Vitro Cytotoxic Efficiencies of Transition Metal Complexes of Two Oxime Ligands" supported by TÜBITAK.

Cite this article: ERTÜRK Ö, ÇOL AYVAZ M, CAN Z, KARAMAN Ü, KORKMAZ K. Antioxidant, Antimicrobial Activities and Phenolic and Chemical Contents of Physalis peruviana L. from Trabzon, Turkey. Indian J of Pharmaceutical Education and Research. 2017;51(3)Suppl:S213-16. 